\title{
PENINGKATAN HASIL BELAJAR IPA FISIKA DENGAN MENGGUNAKAN MODEL PEMBELAJARAN PROBLEM SOLVING PADA SISWA KELAS VII SMP NEGERI 18 PALU
}

\author{
Risnawaty, I Komang Werdhiana dan H. Amiruddin hatibe \\ risnawatypalusery@yahoo.co.id \\ Program Studi Pendidikan Fisika FKIP Universitas Tadulako \\ Jl. Soekarno Hatta Km. 9 Kampus Bumi Tadulako Tondo Palu - Sulawesi Tengah
}

\begin{abstract}
Penelitian ini bertujuan untuk mengetahui peningkatan hasil belajar IPA Fisika melalui model pembelajaran problem solving pada kelas VII SMP negeri 18 Palu. Metode yang digunakan adalah kuasi eksperimen dengan the equivalent pretest-posttest design. Populasi penelitian ini adalah seluruh siswa kelas VII SMP Negeri 18 Palu. Teknik pengambilan sampel adalah purposive sampling. Kelas VII A sebagai kelas eksperimen dan kelas VII D sebagai kelas kontrol. Instrumen hasi belajar berupa tes pilihan ganda yang telah divalidasi oleh validator dan coba lapangan. Peningkatan rata-rata $\mathrm{N}$-gain yang mengikuti model pembelajaran problem solving adalah 72,72 yang berkriteria tinggi dan peningkatan rata-rata yang mengikuti model konvensional menggunakan metode ceramah adalah 63,98 yang berkeriteria sedang. Berdasarkan hasil pengolahan data dengan menggunakan program SPSS 21, untuk kelas eksperimen diperoleh nilai rata-rata tes hasil belajar awal yaitu 36,95 dan tes hasil belajar akhir yaitu 83,45, dan untuk kelas kontrol nilai rata-rata tes hasil belajar awal yaitu 40,45 dan tes hasil belajar akhir yaitu 78,86. Berdasarkan hasil pengujian uji hipotesis diperoleh nilai signifikannya yaitu 0,039. Dimana Nilai signifikan hasil uji hipotesis diperoleh lebih kecil dibandingkan dengan nilai a atau 0,039<0,05. Dengan demikian $\mathrm{H}_{1}$ diterima dan $\mathrm{H}_{0}$ ditolak. Dengan demikian dapat disimpulkan bahwa terdapat peningkatan hasil belajar IPA Fisika melalui penerapan model pembelajaran problem solving pada siswa kelas VII SMP Negeri 18 Palu.
\end{abstract}

Kata Kunci : Problem Solving, Hasil Belajar

\section{PENDAHULUAN}

Fisika merupakan ilmu pengetahuan yang mempelajari berbagai fenomena alam sehingga rahasia yang dikandungnya dapat diungkap dan dipahami. Dalam usaha mengungkap rahasia alam tersebut, sains melakukannya dengan menggunakan metode ilmiah. Fisika menjadi sangat penting seiring dengan perkembangan zaman yang semakin maju baik dalam perkembangan pengetahuan maupun perkembangan tehknologi. Dalam pembelajaran fisika yang berkualitas tidak lepas dari peran guru, dimana guru dituntut mampu menciptakan situasi pembelajaran yang aktif, kreatif, inovatif, efektif dan menyenangkan dalam proses pembelajaran khususnya pembelajaran fisika.

Pembelajaran fisika dapat dikatakan berhasil dilihat dari tingkat keaktifan belajar siswa dan kreativitas siswa dalam memahami dan menguasai materi fisika. Semakin tinggi keaktifan, pemahaman dan penguasaan materi fisika, semakin tinggi pula tingkat keberhasilan guru dalam proses pembelajaran fisika.
Siswa mampu menghafal konsep-konsep dalam sains tetapi, ketika berhadapan dengan masalah di kehidupan sehari-hari yang memerlukan penerapan sains, siswa tidak mampu mengaplikasikannya untuk memecahkan masalah $\left[{ }^{1}\right]$ ketidak mampuan siswa mengaplikasikan dapat menyebabkan siswa tidak mampu menghafal konsep-konsep dalam sains.

Pemilihan model pembelajaran yang kurang tepat adalah salah satu penyebab masalah itu terjadi. Dimana salah satu model pembelajaran yang sesuai diterapkan dalam permasalahan ini adalaah model pembelajaran Problem Solving. Model pembelajaran Problem Solving harus diawali dengan mengidentifikasi masalah yang berarti sangat mengutamakan proses tentang bagaimana cara memperoleh pengetahuan agar siswa dapat menginovasi, menciptakan, mendisain model, rancangan, produk (karya) berdasarkan pengetahuan yang dipelajari.

Kurangnya interaksi antara guru dan siswa, siswa dengan siswa, sehingga usaha untuk meningkatkan daya serap siswa tidak tercapai. Proses pembelajaran yang terpusat 
pada guru menyebabkan siswa kurang aktif dan tidak antusias dalam mengikuti proses pembelajaran, mereka hanya menerima hal yang diberikan guru $\left.{ }^{2}\right]$. Berpijak dari kurangnya interaksi antara guru dan siswa, siswa dengan guru untuk meningkatkan hasil belajar diperlukan model pembelajaran problem solving. dimana model pembelajaran ini menekankan pada kemampuan siswa dalam menyelsaikan suatu permsalahan sesuai dengan langkah-langkah yang tepat.

Model pembelajaran Problem Solving siswa dituntut aktif untuk mendapatkan konsep yang dapat diterapkan dengan jalan memecahkan masalah, peserta didik akan mengeksplorasi sendiri konsep-konsep yang harus mereka kuasai, dan peserta didik diaktifkan untuk bertanya dan berargumentasi melalui diskusi mengasah keterampilan investigasi dan menjalani prosedur kerja ilmiah lainnya $\left[{ }^{3}\right]$.

\section{Problem}

\section{Solving}

akan bermakna.

siswa

terjadi

pembelajaran memecahkan suatu masalah maka mereka belajar akan menerapkan pengetahuan yang dimilikinya atau berusaha mengetahui pengetahuan yang diperlukan, kepuasan intelektual akan timbul dari dalam sebagai hadiah intrinstik bagi siswa. Problem Solving dapat meningkatkan kemampuan berpikir kritis, menumbuhkan inisiatif siswa dalam bekerja, motivasi internal untuk belajar, dan dapat mengembangkan hubungan interpersonal dalam bekerja kelompok.

Berdasarkan uraian di atas, dapat terlihat bahwa model pembelajaran Problem Solving memiliki beberapa keunggulan untuk dapat menggali konsep siswa sehingga dapat meningkatkan hasil belajar siswa. Hal inilah yang melatar belakangi penulis untuk melakukan penelitian yang berjudul "Peningkatan Hasil Belajar IPA Fisika dengan Menggunakan Model Pembelajaran Problem Solving Pada Siswa Kelas VII SMP Negeri 18 Palu".

\section{METODE PENELITIAN}

Jenis penelitian yang digunakan adalah jenis penelitian eksperimen kuasi. Adapun populasi pada penelitian ini adalah seluruh siswa kelas VII SMP Negeri 18 Palu tahun ajaran 2015/2016 yang tersebar dalam 6 kelas. Kelas VII A sebagai kelas eksperimen yang siswanya mengikuti model pembelajaran problem solving dan kelas VII D sebagai kelas kontrol yang siswanya mengikuti model pembelajaran direct instruction dengan metode ceramah.

Pengambilan sampel pada penelitian ini adalah purposive sampling yaitu teknik pengambilan sampel berdasarkan pertimbangan tertentu. Purposive sampling merupakan bagian dari jenis nonprobability sampling, dimana jenis ini tidak memberikan peluang/kesempatan yang sama bagi setiap unsur atau anggota populasi lain untuk dijadikan sampel.

Adapun desain penelitian yang digunakan adalah the equivalen pretest-posttest design atau rancangan prates-pascates yang ekuivalen, yaitu menggunakan kelas-kelas yang sudah ada sebagai kelompoknya, dengan memilih kelas-kelas yang diperkirakan sama keadaan/kondisinya $\left[{ }^{4}\right]$. Desain penelitian yang digunakan seperti pada Tabel 1.

Tabel 1. the equivalen pretest-posttest design
\begin{tabular}{|c|c|c|c|}
\hline Kelompok & Pretes & Perlakuan & Postes \\
\hline Eksperimen & $\mathrm{O}_{1}$ & $\mathrm{X}_{1}$ & $\mathrm{O}_{2}$ \\
\hline Kontrol & $\mathrm{O}_{1}$ & $\mathrm{X}_{2}$ & $\mathrm{O}_{2}$ \\
\hline
\end{tabular}

\section{HASIL DAN PEMBAHASAN}

Tujuan penelitian ini untuk mengetahui peningkatan hasil belajar IPA Fisika melalui model pembelajaran problem solving pada kelas VII SMP negeri 18 Palu. Data hasil belajar diperoleh melalui tes. Tes yang digunakan yaitu tes pilihan ganda dengan jumlah 26 soal. Pada awal penelitian kedua kelas terlebih dahulu diberikan tes awal. Data tes awal digunakan untuk mengetahui bahwa kedua data berasal dari varians yang sama (homogen) atau memiliki kemampuan yang sama. Hasil data pengujian dilakukan menggunakan bantuan SPSS 21. Skor hasil belajar siswa diperoleh dari tes awal dan tes akhir yang dilakukan pada masing-masing kelas yaitu eksperimen dan kontrol.Nilai rata-rata tes awal dan tes akhir dari kedua kelas dapat dilihat pada Tabel 2 .

Tabel 2 Nilai Tes Hasil Belajar Tes Awal dan Tes Akhir

\begin{tabular}{|l|r|r|r|r|}
\hline & $\begin{array}{c}\text { Minimu } \\
\mathrm{m}\end{array}$ & Maximum & Mean & $\begin{array}{c}\text { Std. } \\
\text { Deviation }\end{array}$ \\
\hline $\begin{array}{l}\text { Hasil Belajar } \\
\text { Awal Kelas } \\
\text { Eksperimen }\end{array}$ & 26,00 & 52,00 & 36,95 & 7,71 \\
\hline $\begin{array}{l}\text { Hasil Belajar } \\
\text { Akhir Kelas } \\
\text { Eksperimen }\end{array}$ & 65,00 & 96,00 & 83,45 & 7,48 \\
\hline $\begin{array}{l}\text { Hasil Belajar } \\
\text { Awal Kontrol }\end{array}$ & 26,00 & 58,00 & 40,45 & 8,32 \\
\hline $\begin{array}{l}\text { Hasil Belajar } \\
\text { Akhir Kontrol }\end{array}$ & 65,00 & 91,00 & 78,86 & 6,80 \\
\hline
\end{tabular}


Berdasarkan Tabel 2 dapat dilihat bahwa secara kuantitas untuk tes awal dan tes akhir terdapat perbedaan hasil belajar pada materi kalor antara kelas eksperimen dan kelas kontrol. Hasil pengolahan data ini selanjutnya digunakan untuk menganalisis data melalui uji normalitas, uji homogenitas dan uji hipotesis.

Data yang akan diuji normalitas adalah data hasil Pretest pada kelas eksperimen dan kelas kontrol. Hasil perhitungan analisis $u j i$ normalitas Pretest menggunakan uji normalitas Lilliefors (Kolmogorov Smirnov) melalui SPSS 21 dapat dilihat pada Tabel 3.

Tabel 3. Normalitas Distribusi Tes awal Pada Kelas Eksperimen dan Kelas Kontrol

\begin{tabular}{|l|r|r|r|r|r|r|}
\hline & \multicolumn{3}{|c|}{$\begin{array}{c}\text { Kolmogorov- } \\
\text { Smirnov }\end{array}$} & \multicolumn{3}{c|}{ Shapiro-Wilk } \\
\cline { 2 - 7 } & $\begin{array}{c}\text { Statis } \\
\text { tic }\end{array}$ & Df & Sig. & $\begin{array}{c}\text { Statis } \\
\text { tic }\end{array}$ & Df & Sig. \\
\hline $\begin{array}{l}\text { Kelas } \\
\text { Eksperimen }\end{array}$ & 0,18 & 22 & 0,06 & 0,93 & 22 & 0,15 \\
\hline $\begin{array}{l}\text { Kelas } \\
\text { Kontrol }\end{array}$ & 0,15 & 22 & 0,20 & 0,97 & 22 & 0,62 \\
\hline
\end{tabular}

Kriteria uji normalitas tes yaitu;

Sig $>0,05=$ data berdistribusi normal.

Sig $<0,05=$ data tidak berdistribusi normal

Berdasarkan Tabel 3 diperoleh informasi bahwa kedua uji persyaratan terpenuhi. $P$-value hasil uji normalitas pada kelas eksperimen nilai signifikan $(0,061)>0,05$ dan kelas kontrol $(0,198)>0,05$, bedasarkan kriteria uji normalitas yang ditetapkan dapat disimpulkan bahwa data hasil pretest berdistribusi normal.

Tabel 4. Normalitas Distribusi Tes Akhir Pada Kelas Eksperimen dan Kelas Kontrol

\begin{tabular}{|l|c|c|c|c|c|c|}
\hline & \multicolumn{3}{|c|}{$\begin{array}{c}\text { Kolmogorov- } \\
\text { Smirnov }\end{array}$} & \multicolumn{3}{|c|}{ Shapiro-Wilk } \\
\cline { 2 - 7 } & $\begin{array}{c}\text { Statis } \\
\text { tic }\end{array}$ & Df & Sig. & $\begin{array}{c}\text { Statis } \\
\text { tic }\end{array}$ & Df & Sig. \\
\hline $\begin{array}{l}\text { Kelas } \\
\text { Eksperimen }\end{array}$ & 0,16 & 22 & 0,16 & 0,96 & 22 & 0,43 \\
\hline $\begin{array}{l}\text { Kelas } \\
\text { Kontrol }\end{array}$ & 0,18 & 22 & 0,07 & 0,94 & 22 & 0,21 \\
\hline
\end{tabular}

Kriteria uji normalitas tes yaitu;

Sig $>0,05=$ data berdistribusi normal.

Sig $<0,05=$ data tidak berdistribusi normal

Berdasarkan Tabel 3 diperoleh informasi bahwa kedua uji persyaratan terpenuhi. $P$-value hasil uji normalitas pada kelas eksperimen nilai signifikan $(0,16)>0,05$ dan kelas kontrol $(0,07)>0,05$, bedasarkan kriteria uji normalitas yang ditetapkan dapat disimpulkan bahwa data hasil pretest berdistribusi normal.

Perolehan uji homogenitas posttest kelas eksperimen dan kelas kontrol pada taraf signifikansi $\alpha=0,05$ diperoleh $p$-value $(0,62)>$ 0,05 , sehingga dapat disimpulkan bahwa data hasil postest pada kelas eksperimen dan kontrol memiliki varians homogen.

Pengujian hipotesis menggunakan uji-t (uji satu pihak). Kriteria penerimaan yakni $\mathrm{H}_{0}$ diterima jika nilai signifikannya yang diperoleh lebih kecil dibandingkan dengan nilai a atau $0,04<0,05$. Dengan demikian $\mathrm{H}_{1}$ diterima dan $\mathrm{H}_{0}$ ditolak. Artinya bahwa hasil belajar IPA Fisika siswa yang melalui model pembelajaran problem solving lebih meningkat dari hasil belajar siswa yang mendaapatkan pembelajaran konvensional.

Adapun nilai rata-rata peningkatan pemahaman konsep yang diperoleh melalui hasil analisa data menggunakan N-Gain untuk kelas eksperimen dan kontrol ditunjukan pada Tabel 5.

Tabel 5. Hasil Uji Peningkatan Pemahaman Konsep Pada Kelas Eksperimen dan Kelas Kontrol

\begin{tabular}{|c|c|c|c|}
\hline Uraian & Tes awal & $\begin{array}{c}\text { Tes } \\
\text { akhir }\end{array}$ & $\begin{array}{c}\text { Rerata } \\
\text { Gain }\end{array}$ \\
\hline $\begin{array}{c}\text { Kelas } \\
\text { Eksperimen }\end{array}$ & 37,32 & 83,45 & 72,72 \\
\hline Kelas Kontrol & 40,45 & 78,86 & 63,98 \\
\hline
\end{tabular}

Tabel 5 dapat dilihat perbedaan peningkatan hasil belajar IPA Fisika siswa antara kelas eksperimen dan kelas kontrol. Tabel 5 menunjukkan bahwa rata-rata peningkatan hasil belajar IPA Fisika pada kelas eksperimen Dimana kelas eksperimen terjadi peningkatan dan berada pada kriteria tinggi yang lebih baik daripada kelas kontrol dengan nilai $\mathrm{N}$-Gain yang diperoleh yaitu 72,72.

Hasil analisa data Gain menunjukan bahwa hasil belajar siswa SMP Negeri 18 Palu yang mendapatkan pembelajaran Problem Solving lebih meningkat dari kelompok siswa yang mendapatkan pembelajaran konvensional.

$\mathrm{Hal}$ ini didukung oleh keunggulan model pembelajaran problem solving yang dirasakan peneliti saat melakukan penelitia. Hampir seluruh siswa aktif dalam proses pembelajaran sehingga guru hanya berperan sebagai fasilitator dan siswa dapat terlihat lebih aktif dalam pembelajaran. Siswa yang tadinya pasif dalam pembelajaran dengan menerapkan model pembelajaran ini siswa menjadi bersemangat dan lebih fokus pada pembelajaran. Han ini sejalan dengan peneltian 
yang dilakukan oleh Mungarofatul dan Priyanto (2013) yang menyatakan bahwa penerapan pendekatan problem solving dapat meningkatkan partisipasi aktif dan hasil belajar siswa. Para siswa dapat menguasai materi yang diajarkan sehingga hasil belajar pada kelas eksperimen lebih tinggi dibandingan kelas konrol. Kelas kontrol menggunakan model pembelajaran konvensional, ini menyebabkan proses belajar mengajar lebih monoton. Siswa lebih cenderung pasif karena hanya menerima sajian materi dari guru $\left.{ }^{[5}\right]$. Hal ini karena sebelum mereka melakukan proses belajara terlebih dahulu mereka harus membaca materi mengenai sub bab yang akan dipelajari, setelah mereka membaca dan memahami materi kita melakukan proses belajar dengan cara praktikum. Dalam proses belajar mengajar pada praktikum mereka harus mengetahui rumusan masalah dari praktikum, prediksi siswa sebelum melakukan praktikum, melakukan praktikum dengan cara kelompok, langkah-langkah eksperimen didiskusikan sebelum melakukan eksplorasi, menganalisis dan terakhir mengambil kesimpulan mengenai percobaan yang mereka lakukan.

Hasil belajar dan keterampilan proses sains yang didapat siswa melalui model pembelajaran tersebut lebih tinggi dibanding dengan siswa yang mendapat pembelajaran konvensional $\left[{ }^{6}\right]$. Pengaruh penerapan praktikum virtual berbasis problem solving juga berhasil meningkatkan kemampuan berpikir kritis mahasiswa $\left[{ }^{7}\right]$. Terdapat perbedaan prestasi belajar antara siswa yang mengikuti model pembelajaran problem solving dengan siswa yang mengikuti model pembelajaran konvensional $\left.{ }^{8}\right]$.

Kelebihan dari model pembelajaran ini dibandingkan dengan pembelajaran langsung adalah keaktifan siswa. Melalui model pembelajaran ini siswa dilibatkan untuk aktif berfikir dan menemukan secara langsung pengertian atau konsep yang ingin diketahuinya. Selain dari kelebihan tersebut, adapula kekurangan dari model ini yaitu membutuhkan waktu yang cukup lama dalam bereksperimen untuk memperoleh kesimpulan. Kita sebagai guru (fasilitator) juga butuh kesabaran yang lebih dalam membimbing siswa agar dapat fokus dalam melakukan kegiatan pembelajaran.

\section{KESIMPULAN DAN SARAN}

Berdasarkan hasil penelitian dan analisa data hasil penelitian, diperoleh nilai hasil belajar siswa pada tes awal untuk kelas eksperimen yaitu 36,95 dan untuk kelas kontrol yaitu 40,45 . Setelah diberikan perlakuan diperoleh nilai rata-rata hasil belajar kalor pada tes akhir untuk kelas eksperimen 83,45 dan untuk kelas kontrol 78,86 . Nilai signifikan hasil uji hipotesis diperoleh lebih kecil dibandingkan dengan nilai a atau 0,039 $<0,05$. Dengan demikian $H_{1}$ diterima dan $\mathrm{H}_{0}$ ditolak. Dengan demikian dapat disimpulkan bahwa hasil belajar siswa yang mendapatkan pembelajaran problem solving lebih meningkat dari siswa yang mendapatkan pembelajaran konvensional pada kelas VII SMP Negeri 18 Palu.

Berdasarkan kesimpulan ada beberapa saran yang dapat dikemukakan: (1) Dalam menggunakan model pembelajaran yang terpenting adalah keaktifan siswa dan motivasi belajarnya, sehingga merupakan tugas guru untuk meningkatkan hal tersebut. (2) Model pembelajaran problem solving dan model konvensional menggunakan metode eksperimen membutuhkan waktu yang cukup lama, sebaiknya peneliti dapat memperhitungkan waktu disetiap fase pembelajaran agar lebih efisien, karena waktu menjadi salah satu kendala dalam proses pembelajaran. (3) Untuk peneliti selanjutnya dapat menerapkan model problem solving dengan materi yang berbeda dan karakteritik yang berbeda sehingga dapat digunakan sebagai bahan pertimbangan dalam penerapannya disekolah.

\section{DAFTAR PUSTAKA}

[1] Nurjannah, (2008). "Pengaruh Pembelajaran Interaktif Berbasis Konsep Terhadap Aktifitas dan Pemahaman Konsep Fisika Siswa Khususnya Materi Fisika Dalam Bahasan "Cahaya (Optik Geometri)" ". Skripsi pada Universitas Pendidikan Indonesia : diterbitkan.

[2] Mariati, P.S. (2012). Pengembangan Model Pembelajaran Fisika Berbasis Problem Solving Untuk Meningkatkan Kemampuan Metakognisi Dan Pemahaman Konsep Mahasiswa. Jurnal Pendidikan Fisika Indonesia 8 (2012) 152-160. [Online]. Tersedia di http://journal.unnes.ac.id/index.php/jpfi.

[3] Nurbaya, (2015). "Penerapan Model Problem Solving Laboratory terhadap Peningkatan Pemahaman Konsep Kalor pada Siswa Kelas X SMA Negeri 4 Palu". FKIP Universitas Tadulako Palu: tidak diterbitkan

[4] Sudjana, (2005). "Metode Statistik Edisi 6". Bandung: Tarsito

[5] Suparno, P. (2013). Miskonsepsi dan Perubahan Konsep dalam Pendidikan Fisika. Jakarta : PT Gramedia Widiasarana Indonesia. 
[6] Hariani, F. (2013). "Pengaruh Model Problem Solving Laboratory terhadap Keterampilan Proses Sains Dan Hasil Belajar Fisika Siswa Kelas Xi di SMA Negeri 2 Tanggul". Skripsi Sarjana pada FKIP Universitas Jember: tidak diterbitkan.

[7] Sutarno, (2013). "Pengaruh Penerapan Praktikum Virtual Berbasis Problem Solving terhadap Kemampuan Berpikir Kritis Mahasiswa". Prosiding Semirata FMIPA Universitas Lampung.

[8] Simajuntak, M.P . (2012). "Peningkatan Pemahaman Konsep Fisika Mahasiswa Melalui Pendekatan Pembelajaran Pemecahan Masalah Berbasis Video." Jurnal Pendidikan Fisika. 1(2), 55 - 60. 